\title{
Mixing Practices to Create Transdisciplinary Innovation: A Design-Based Approach
}

\author{
Kees Dorst
}

\author{
"We can't solve problems by using the same kind of ") \\ thinking we used when we created them.
}

Attributed to Albert Einstein (1879-1955)

Theoretical Physicist and Nobel Laureate (1921)

\begin{abstract}
As the problems that are our organizations are facing become more complex, dynamic, and networked, they will need to become more flexible in their ability to respond. These complex networked problem situations often cannot be tackled from a single-discipline perspective, and thus transdisciplinary innovation - that is, innovation across and between disciplinary fields - is becoming more important. But how can we achieve innovation in those in-between spaces, when all of our knowledge and established approaches are held within the disciplines? In this article, we look beyond the limiting confines of traditional disciplines by seeing them as collections of smaller units of action: practices. After a foray into the anatomy of practices, we discuss how a design-based approach to transdisciplinary thinking creates a framework for the mixing of practices, articulating new insights and creating new possibilities for action in the space between the established professions.
\end{abstract}

\section{Introduction}

Over the last three decades, humanity has networked itself, to great advantage - welcome to the brave new world of the networked society - but, in doing so, we have also inadvertently networked our problems, thereby creating complex tangled webs of relationships in which progress is difficult to achieve. Our businessas-usual way to approach problems seems to be no match for the curious open, complex, dynamic, and networked nature of today's problems (Castells, 2011; Stacey et al., 2002). Our organizations and professions are struggling, and they seem to have no established way to comprehend and respond to this new type of problem situation (Boutellier, 2013). In the end, if the problems that an organization is set to deal with become more open, complex, dynamic, and networked, the organization itself will have to become more open, complex, dynamic and networked (McChrystal et al., 2015). But how can it do this?

To achieve progress in this brave new world, we have to look for new approaches and change the very way we think. Our common modes of thinking are organized in (specialized) professional fields and implemented through sophisticated organizational structures and processes. Yet, as the challenges before us become more complex and networked, innovation often seems to occur between disciplinary fields and outside of established organizations, for example, in the unstructured activities of startup ecosystems. Highly innovative people these days are often the ones who traverse disciplinary boundaries, who happen to bring deep knowledge and skills of several fields to bear on a problem or an opportunity, combining practices in a way that creates new value (Gardner, 2006).

In this article, we will explore how a design-based approach to reframing - and the understanding of practices as layered means-ends hierarchies - can help us find ways to mix practices across disciplinary fields, thereby creating the type of true transdisciplinary innovation we need to respond to today's complex, networked problems.

\section{The Challenge: Addressing Complex Problem Situations}

Before delving into the core part of this article - investigating how the manipulation of practices can lead to transdisciplinary innovation - we need to take two steps back: one to understand the context in which this 


\section{Mixing Practices to Create Transdisciplinary Innovation: A Design-Based Approach}

Kees Dorst

particular type of innovation is called for and a second one to frame the process in which practices can come together in new ways.

When problems move from being very complicated to truly complex, our ways of addressing them should shift accordingly (Snowden et al., 2007). We effectively move from the field of problem solving (Simon, 1973; Hatchuel, 2001) to complexity theory and systems thinking (Ball, 2012). There, we can learn that, in very complex systems, newness comes from the emergence of order (rather than from goal-directed creation), change is achieved through influencing the system (rather than through implementing a plan to "solve the problem"), and a new state of relative stability can be created through creating resilience (rather than through striving for an immutable structure). These system dynamics make it hard to act upon a complex system to address issues or create newness. Any attempt at searching for "the" solution would be riddled with assumptions: in a truly complex situation, there is no solution. The way to achieve progress is to create high-quality intervention to bring the whole system forward into a more desired state. (For details on how such interventions can be created, see "Transformative Theology" in Stacey and co-authors [2002]).

So, what are the key issues that face a professional in dealing with a complex networked situation? First of all, it is not clear where to start (this is, it is not clear how to interpret the problem situation) and, second, it is uncertain which relationships in the tangle are going to be important in shaping what would be the appropriate way forward. To overcome these challenges, we need a propositional way of working, both in the interpretation step to create an initial understanding and in the action/intervention step (to create feedback that will show which relationships in the complex problem situation are key, and which ones can safely be ignored). Although the interpretation step could possibly be covered by normal inductive reasoning, the intervention step requires design abduction, a much more open way of reasoning (Dorst, 2015). In design abduction, the practitioner enters into a thoughtful exploration by (repeatedly) proposing a framing of the problem situation, observes what possible solution directions emerge from these framings, and then reflects on the fruitfulness of their actions (is this going in the right direction?). In this way, the practitioner can navigate the complexity of the situation and "learn their way" towards a solution. In this process, assumptions, as well as established ways of working (e.g., paradigms [Kuhn, 1962]), are continually questioned.

\section{A First Answer from Design: Framing Complex Problem Situations}

Rushing into solving a problem without fully appreciating its complexity can easily lead to solving the wrong problem. And the hidden assumptions of such a rushed approach (or "knee-jerk reaction") mean that the problem solver also misses opportunities by not making a full use of the diversity of practices at their disposal. To carefully approach complex problem situations, we need to analyze them to understand how they have been framed and explore alternative framings that might lead to very different types of solutions. The ways in which expert designers create such new frames have been modelled in a frame-creation process (Dorst, 2015). Key to the creation of new frames is thinking around the problem situation rather than confronting it head-on. Designers have created processes that cleverly bypass the assumptions that have led to the original problem formulation and that take on the full complexity of the broader field. The creation of new frames in design can be modelled as a process of nine steps (Figure 1).

Within frame creation, new approaches to the complex problem situation are achieved through accessing practices from other fields. Central to the frame-creation process is the fifth step, where the analysis of the values of the broader field of stakeholders in the fourth step leads to a set of themes, from which new frames can be created by linking to practices from other professional fields. The first four steps lay the groundwork; the latter steps explore the implications of the potential frames and proposed solution directions (for an example, see the description of the Kings Cross project in the next section and in Dorst $[2015,2016])$.

\section{Background: An Anatomy of Practices}

To understand how this frame-creation process works, we need to take one more step back and consider the anatomy of practices. A practice is a deliberate and coherent set of activities intended to achieve something. It combines a way of seeing, thinking, and acting. Models of practices (Max-Neef, 2005) generally present them as being layered (Jantsch, 1972), with the layers containing statements on the "Why", the "How", and the "What" (van der Bijl-Brouwer, 2014, 2017) (Figure 2).

The top layer describes the values you are setting out to achieve. Then there is a second layer that describes the principles and strategies chosen to achieve these values. The third layer is more tactical and describes the 


\section{Mixing Practices to Create Transdisciplinary Innovation: A Design-Based Approach}

Kees Dorst

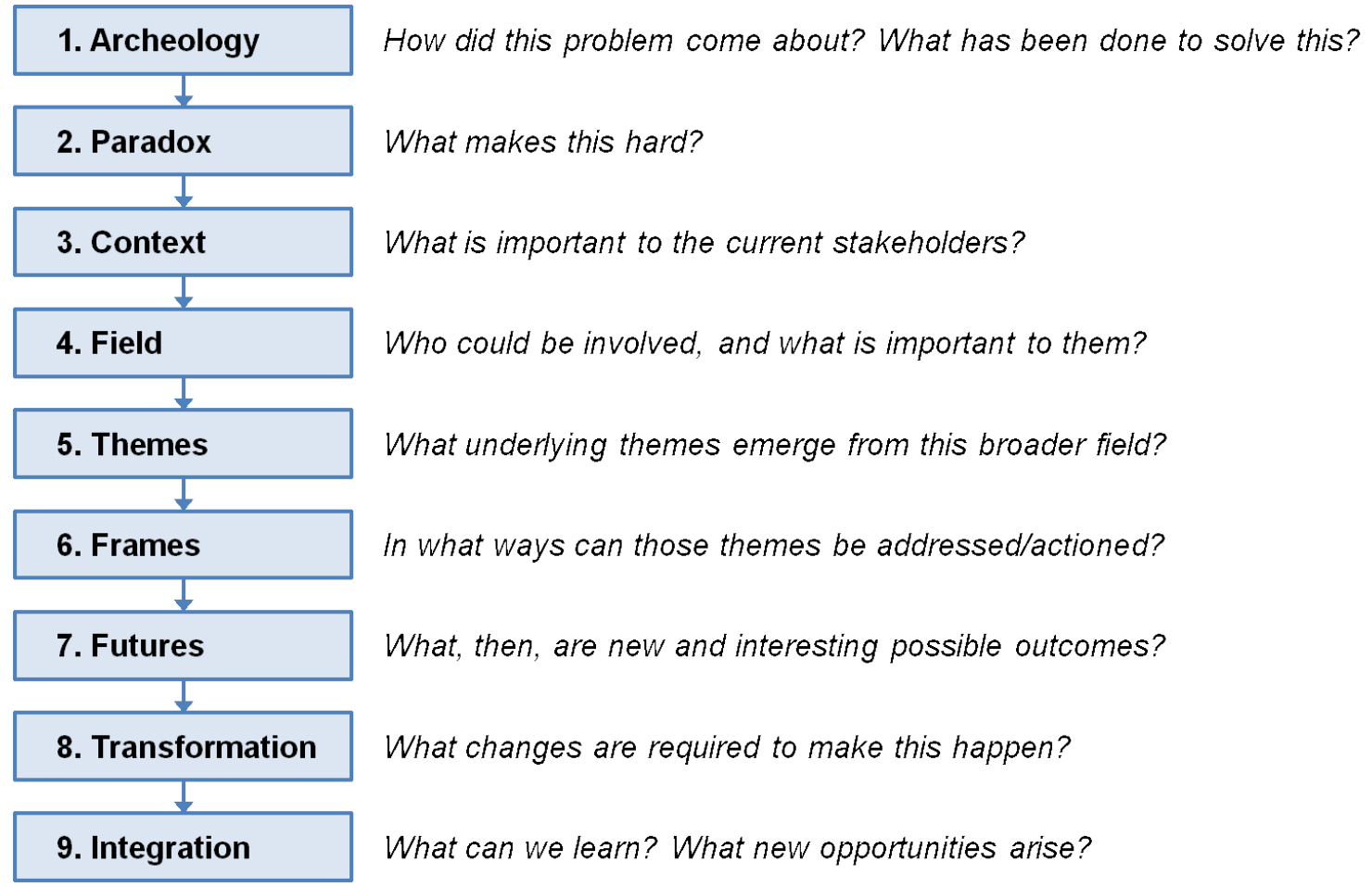

Figure 1. The frame-creation process of expert designers

"How", the method(s) through which the goal is to be achieved. The fourth layer is that of the concrete actions that are seen as part of the practice - the "What".

A framing is a statement that ties together the top two layers of the practice model: value and principle. Often, in conventional thinking, the value to be achieved and the principles through which to achieve them are merged. This merger is highly problematic because it hardwires the practice into an immutable frame. People then see one particular way of approaching the problem as the only rational one. They talk along the lines of "we have to achieve this, so we need to do that".

What makes this layered model of a practice interesting is that it opens up practices for deeper scrutiny and invites consideration of a broader range of actions, because going back to first principles (starting with values: what is this about?) makes one sensitive to the fact that any value can be achieved by multiple principles, through many different methods that lead to even more possible actions. Although a practice might look "logical" when perceived from the world of action (bottom-up in Figure 3), we can see that they are actually open-ended.
So, practices contain choices, which are often implicit choices about the values we find important, the principles we use to think about them, and the methods and actions we are going to apply. Practices also always contain a way of seeing the problem. Although that is often very implicit, the example below will illustrate how it can be hidden in the very words we use to describe a problem situation.

Frame creation is a process that expert designers developed to get around this fixation. The frame-creation

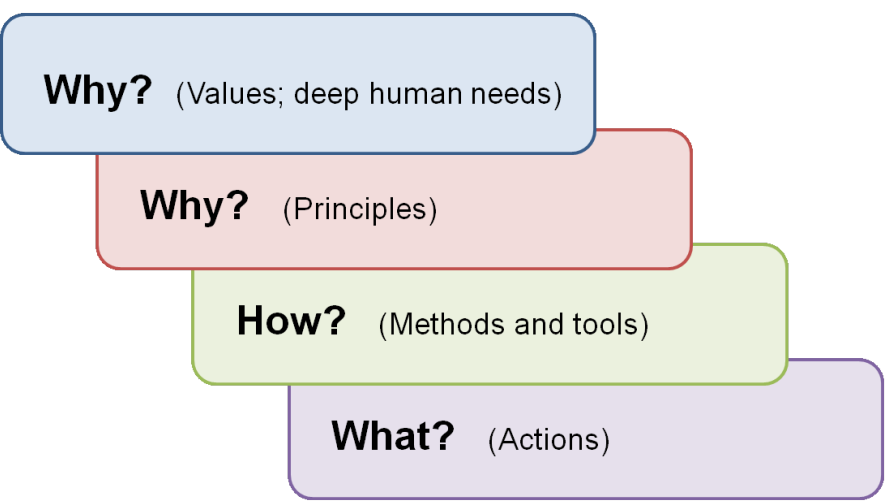

Figure 2. The four layers of a practice 


\section{Mixing Practices to Create Transdisciplinary Innovation: A Design-Based Approach}

Kees Dorst

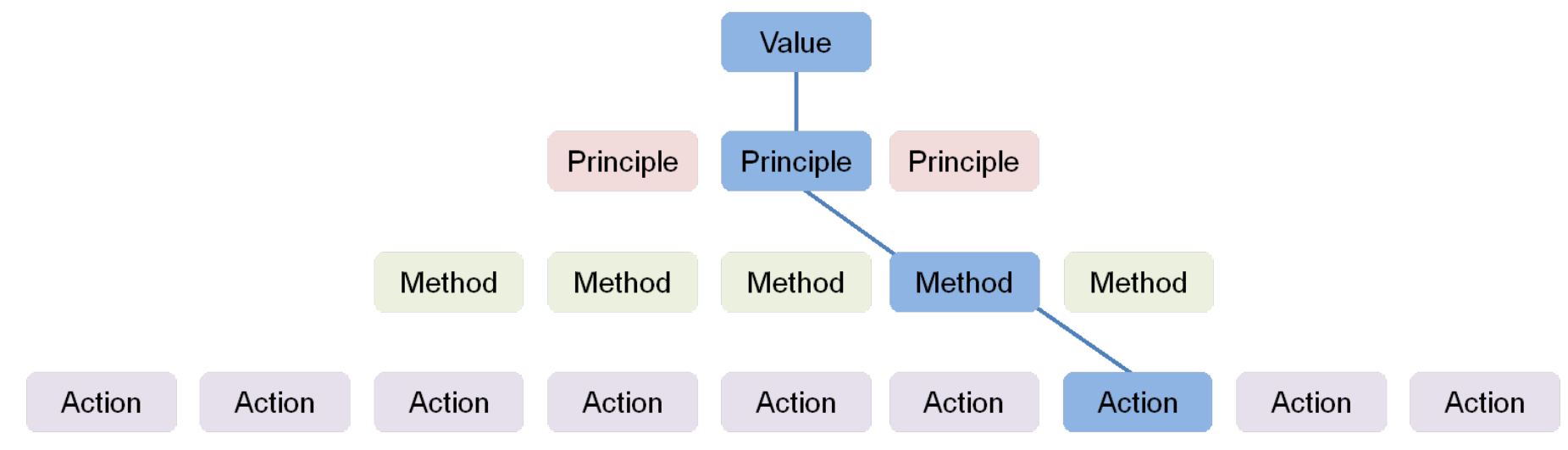

Figure 3. The open-endedness of practices

process first leads a practitioner up the four layers of practice: from considering the existing actions and methods to approaching the problem situation, back to principles and the underlying values (themes). Then, from a broad consideration of these values, new principles, methods, and actions can be proposed. This process includes a new selection of overlooked values, principles, methods, and actions that potentially could address the same problem. It also includes deriving new combinations of existing sets of them and possibly inventing entirely new methods and actions that are purpose-designed to the specific context.

An example might help to clarify how the reframing of a problem situation and the thinking of practices in terms of these four layers can be used to adopt practices that are new to the problem situation.

The late-night problems in Kings Cross, an entertainment district in the city of Sydney, have always been labelled as "alcohol-related violence". This simple statement contains the assumption (frame) that safety and security should be assured (value), by combating violence - and that the violence is causally related to alcohol consumption. The obvious way forward is then to reduce alcohol consumption because, through that step, violence will also decrease (principle). This can be done through legislation (method) and increasing the police presence to enforce the new rules (action).

This is a clear and convincing path to action, with an almost inescapable rationality, except that, in this case upon closer scrutiny - we may see that the violence that occurs late at night is not necessarily alcohol related. A reframing of the problem is necessary, and one of the most fruitful frames in the initial Kings Cross project executed by the Designing Out Crime research centre was built on the metaphor of seeing the area as a music fest- ival. This is a radical reframing of the problem situation, miles away from seeing it as a crime problem. Thus, the frame of a "music festival" opens up the problem situation. The new value set to strive for includes a vibrant, night time economy, the principle to achieve this by is metaphorically "creating a music festival", the methods to achieve this are varied, but they centre around seeing the city council as the event manager, using methods from many different professional fields (e.g., event management, behavioural psychology, economics, visual communication, education, fluid dynamics). This approach leads to fruitful new actions: the violence and misdemeanors could be managed by making sure there is appropriate transport out of the area late at night, providing enough public toilet facilities, diversifying the entertainment offerings, creating "chill-out" spaces, rerouting traffic, improving management of taxi queues, having "Kings Cross Guides" welcome the party goers into the area, creating safe spaces for sobering up, etc - thereby reducing frustration, boredom, and violence (Dorst, 2015, 2016).

\section{Second Answer: Transdisciplinarity and the Mixing of Practices}

Problems often arrive at an organization's doorstep as a call for action - the pressure is that we need to act, urgently, to change an unwanted situation into a better one. This means that, more often than not, the first attempts to solve a problem are based on the existing actions, methods, and principles of an organization. This makes absolute sense: the expertise and resources are available so that the problem can be solved both efficiently and at speed. Yet, knee-jerk reactions do not always suffice, and by holding on to such "best practices", we do not look beyond what worked in the past. In a rapidly changing environment, the assumptions and simplifications that were part and parcel of 


\section{Mixing Practices to Create Transdisciplinary Innovation: A Design-Based Approach}

Kees Dorst

that "best practice" might not hold anymore (Boutellier, 2013). To access other practices, we need to reframe the problem situation. To break free, we need to recognize that the (routine) reactions are not the sole or necessary solution to the problem, and they perhaps offer a very sub-optimal solution. The above model of practices shows that, on reflection, there are always alternative ways of approaching a problem arena.

Yet, this is not easy. Confronted with the new complex networked reality we have created for ourselves, we struggle to step back and create new approaches: our disciplinary and organizational structures hold us back from doing so. By just looking at practices, we (temporarily) ignore these structures, routines, and norms, and we create a new playing field for fresh approaches to the problem situation to emerge. This transdisciplinary playing field comes with the freedom to branch out and learn from many disciplines that might have principles, methods, and actions that might be adopted or adapted into the problem situation.

An example of such exchanging, recombining, or mixing of practices is (a byproduct of) the development of the of a new transdisciplinary Bachelor degree at the University of Technology Sydney: the Bachelor of Creative Intelligence and Innovation (cii.uts.edu.au), which is built from the practices contained in 25 degrees across the university. During the development of this degree, a staff member from the Faculty of Design, Architecture and Building came to discuss the exchange of practices with people from the Faculty of Law. The law representatives were interested in some practices from design. They framed the question by explaining that currently, law is almost always "too late" - when a new technical development emerges, the law profession only starts focusing on its issues once the first case is brought before the court. These court cases tend to take long, be expensive, and inadvertently hold up innovation. Yet, design has sophisticated practices for "looking ahead" (scenario methods, technology roadmaps, forecasting/backcasting, etc.). Conversely, the design representative sought to learn how the law field deals with precedent - court cases are kept and archived as situated knowledge so that, when the need arises, the earlier judgment can be retrieved and the old context in which it arose can be compared with the current one before the court. A subtle language game has been built up to guide the interpretation. This practice is in marked contrast to the field of design, which has no systematic way of dealing with memory at all: when designing for a current challenge, one might be trying to use an earlier design instance for inspiration, but there is no way for the designer to identify the most appropriate earlier design and access the contextual information needed to understand it. Thus, the field of design has a lot to learn from law - not by adopting the practices as they are, but by adapting them to fit the field (Dorst, 2017).

\section{Conclusion: Towards Transdisciplinary Innovation}

As we have seen, the frame-creation process provides us with a thoughtful way to re-interpret and rethink existing problem situations, and to identify practices from various fields and disciplines that could be brought to bear (as shown in the first example above). We reframe when we are forced away from our normal (knee-jerk) action orientation and have to go back to first principles. From this deep rethinking, we can then access the broadest possible collection of principles, methods, and actions, while considering how they may assist us. This type of deeply considered innovation-betweenfields leads to the adoption of principles and practices that are completely new to the problem situation.

While framing "reshuffles" the position of practices relative to complex issues, the description of practices in terms of the four layers also opens up the possibility and the freedom for practices from different fields/backgrounds to be mixed and cross-linked in an open "practice dialogue" (such as happened in the second example above).

Reframing and the capability to create open practice dialogues are key elements of the transdisciplinary thinking we need to deal with today's open, complex, dynamic, and networked problem situations. In leaving behind the stable structures of disciplines and organizations, one learns to truly value the practices they contain. 


\section{Mixing Practices to Create Transdisciplinary Innovation: A Design-Based Approach}

\section{Kees Dorst}

\section{About the Author}

Kees Dorst was trained as an Industrial Design Engineer at Delft University of Technology in the Netherlands. Currently, he is Professor of Design Innovation at the University of Technology Sydney's Faculty of Transdisciplinary Innovation in Australia, where he is also the Founding Director of the university's Design Innovation and Designing Out Crime research centres. He lectures at universities and design schools throughout the world. He has published many articles and several books including Understanding Design (2006), Design Expertise (with Bryan Lawson, 2009), Frame Innovation - Create New Thinking by Design (MIT Press, 2015), Designing for the Common Good (2016), and Notes on Design - How Creative Practice Works (2017).

Citation: Dorst, K. 2018. Mixing Practices to Create Transdisciplinary Innovation: A Design-Based (cc) BY

Approach. Technology Innovation Management Review,

8(8): 60-65. http://doi.org/10.22215/timreview/1179

Keywords: practice, transdisciplinarity,

transdisciplinary education, disciplines, innovation

\section{References}

Ball, P., 2012. Why Society is a Complex Matter: Meeting Twenty-first Century Challenges with a New Kind of Science. Cham, Switzerland: Springer.

van der Bijl-Brouwer, M., \& Dorst, K. 2014. How Deep Is Deep? A FourLayer Model of Insights into Human Needs for Design Innovation. In J. Salamanca, P. Desmet, A. Burbano, G. Ludden, \& J. Maya. (Eds.), Proceedings of the Colors of Care: The 9th International Conference on Design \& Emotion. Bogotá, October 6-10, 2014.

van der Bijl-Brouwer, M., \& Dorst. K. 2017. Advancing the Strategic Impact of Human-Centred Design. Design Studies, 53: 1-23. https://doi.org/10.1016/j.destud.2017.06.003

Boutellier, H. 2013. The Improvising Society: Social Order in a World without Boundaries. The Hague: Eleven.

Castells, M. 2011. The Rise of the Network Society. Chichester, UK: John Wiley \& Sons.

Dorst, K., 2015. Frame Innovation. Cambridge, MA: MIT Press.

Dorst, K., Kaldor, L., Klippan, L., \& Watson, R. 2016. Designing for the Common Good. Amsterdam: BIS Publishers.

Dorst, K. 2017. Notes on Design - How Creative Practice Works. Amsterdam: BIS publishers.

Gardner, H. 2006. Changing Minds. Cambridge, MA: Harvard Business School Press.

Hatchuel, A. 2001. Towards Design Theory and Expandable Rationality: The Unfinished Program of Herbert Simon. Journal of Management and Governance, 5(3): 260-273. https://doi.org/10.1023/A:1014044305704

Jantsch, E. 1972. Towards Interdisciplinarity and Transdisciplinarity in Education and Innovation. In L. Apostel, G. Berger, A. Briggs, \& G. Michaud (Eds.), Interdisciplinarity, Problems of Teaching and Research in Universities: 97-121. Paris: OECD Publications.

Kuhn, T. S. 1962. The Structure of Scientific Revolutions. Chicago: University of Chicago Press.

Max-Neef, M. A. 2005. Foundations of Transdisciplinarity. Ecological Economics, 53(1): 5-16.

McChrystal, S., Collins, T., Silverman, D., \& Fussell, C., 2015. Team of Teams: New Rules of Engagement for a Complex World. London: Penguin.

Simon, H. A. 1973. The Structure of Ill Structured Problems. Artificial Intelligence, 4(3-4): 181-201. https://doi.org/10.1016/0004-3702(73)90011-8

Snowden, D. J., \& Boone, M. E. 2007. A Leader's Framework for Decision Making. Harvard Business Review, 85(11): 68-76.

Stacey, R. D., Griffin, D., Shaw, P. 2002. Complexity and Management: Fad or Radical Challenge to Systems Thinking? London: Routledge. 


\section{Academic Affiliations and Funding Acknowledgements}

Canadà
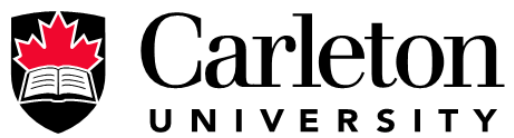

U N I V E R S I T Y

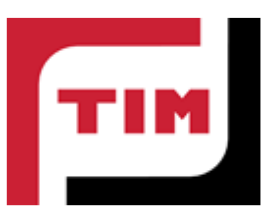

The Federal Economic Development Agency for Southern Ontario (FedDev Ontario; feddevontario.gc.ca) is part of the Innovation, Science and Economic Development portfolio and one of six regional development agencies, each of which helps to address key economic challenges by providing regionallytailored programs, services, knowledge and expertise.

- The TIM Review receives partial funding from FedDev Ontario's Investing in Regional Diversification initiative.

Technology Innovation Management (TIM; timprogram.ca) is an international master's level program at Carleton University in Ottawa, Canada. It leads to a Master of Applied Science (M.A.Sc.) degree, a Master of Engineering (M.Eng.) degree, or a Master of Entrepreneurship (M.Ent.) degree. The objective of this program is to train aspiring entrepreneurs on creating wealth at the early stages of company or opportunity lifecycles.

- The TIM Review is published in association with and receives partial funding from the TIM program. 